\title{
Shared learning process among students of the Health Sciences and Electronic Engineering Department and students of professional training in the area of Technology and Health. A proposal for educational innovation
}

\author{
Enrique Sanchis-Sánchez ${ }^{1}, M^{a}$ Montserrat Sánchez-Lorente ${ }^{2}$, Juan Ramón Alarcón- \\ Gómez $^{3}$, Pablo García-Molina ${ }^{4}$, Evelin Balaguer-López ${ }^{4}$, Nicole Victoria Zurita- \\ Round $^{1}$, Sergio Ferrer-González ${ }^{1}$, Sandra Paniagua-Sánchez ${ }^{1}$, Fátima Bouaouda- \\ Ruiz $^{4}$, José María Blasco-Igual ${ }^{1}$ \\ ${ }^{1}$ Physiotherapy Department, University of Valencia, Spain, ${ }^{2}$ Nursing School La Fe, \\ University of Valencia, Spain, ${ }^{3}$ Electronic Engineering Department, University of Valencia, \\ Spain, ${ }^{4}$ Nursing Department, University of Valencia, Spain.
}

\begin{abstract}
The objective of this proposal for educational innovation is to facilitate the learning of complex concepts and their relationship with reality, through peer-to-peer training, in where two scenarios will be shared: university and professional training.
\end{abstract}

We propose an experience in which University students in the area of Electronic Technology and Health, specifically from the degrees of Industrial Electronics Engineering, Physiotherapy and Nursing, previously trained in the concepts of radiation and its types, infrared radiation, its use in health in both treatment and diagnosis, thermoregulation and thermography with the visual thinking tool, can transversally share a teaching scenario with students of professional training in the technological areas and health in particular to the Superior Technicians in Clinical Electromedicine.

The execution of the project will be conducted during the month of February of 2019.

This proposal of training acquired between equals will produce greater efficiency in the results, generating a better adhesion in the teaching scenarios and a posteriori in the work environment.

Keywords: Teaching transversality; Termoregulation; Non-ionizing radiation; Infrared radiation; thermography; Visual Thinking. 


\section{Introduction}

Facilitating that students' learning process should be effective is one of the goals of the teachers in all educational areas.

The European Higher Education Area (EHEA) proposes significant changes in the teaching-learning processes. On one hand in the learning approaches that university students use during their academic training, and on the other hand, in the methodological used and teaching strategies that have been implemented (Argos et al., 2013).

Learning approaches integrate both the motivation to perform a task and the strategies that will be used to achieve it. It is something complex, dynamic and continuous that affects deep processes of knowledge (metacognition) and the use, in practice, of the strategies necessary to achieve learning objectives (Tocci 2013).

When it comes to learning complex concepts and their relationships to reality, students manifest learning difficulties. In these cases, the use of traditional teaching methods is a failure for both the student and the teacher. Therefore, it is necessary to consider new teaching strategies for teaching-learning processes both in the learning approach and in the methodological approaches.

This proposal is part of a project of Educational Innovation and Improvement of teaching quality, Service of Lifelong Learning and Educational Innovation (SFPIE) of the University of Valencia and is part of the program "Renewal of Teaching Methodologies" and pursues. They include innovation projects of a general nature, aimed at discovering new methodological instruments and new techniques for improving teaching-learning processes (Uv.es, 2018).

In order to complete the experience, a multidisciplinary group has been set up, but it is unrelated to the different areas of knowledge involved (health professionals who combine university teaching, faculty who teach at the university and in professional training, etc.), being common to all of them with their nuances the knowledge, competences, and abilities.

In order to complete the experience, a multidisciplinary group has been set up, from there differents areas of knowledge involved.

The capacity for abstraction and planning are directly related to the ability to visualize, so people who use the visual representation system are more easily and quickly to acquire large amounts of information and establish relationships between different ideas and concepts (Velásquez 2006).

Howard Gardner (1993) in his theory of "Multiple Intelligences" describes eight types of intelligence, which includes the visual-spatial which is responsible for developing skills in the recognition and development of visual images, allowing mental models to be formed by 
the analysis of the space that surrounds us, as well as the creation of spaces and images (Gardner 2010).

Continuing with this line of argument visual thinking is something innate to the human condition. The visual thought, although it was named by Rudolf Arnheim's in 1969 is a concept in vogue and revolutionized by Dan Roam after the publication of the book in 2010 "Your world in a napkin".

Visual Thinking means "take advantage of the innate ability to discover ideas that would otherwise be invisible, develop them quickly and intuitively and then share them with other people so they can understand them immediately. There is no better way to confirm that we really know something than by drawing it" (Roam 2010).

The visual thought is considered as a tool that consists in overturning and manipulating ideas through simple and easily recognizable drawings, creating connections between them by means of mental maps, in order to understand them better, define objectives, identify problems, discover solutions, simulate processes and generate new ideas.

For all these reasons, it has been considered that University students use as a didactic or methodological tool "Visual Thinking" to transmit knowledge to professional training in the technological areas and health in particular to the Superior Technicians in Clinical Electromedicine.

\section{Objectives}

1. University scope:

- $\quad$ Make students aware of the benefits of visual thinking

- improve the capacity for understanding and synthesis.

- facilitates to express ideas when words are not enough.

- triggers shared processes of thought, dialogue, design and action.

- Train students in specific concepts about radiation, infrared, thermoregulation and thermography and its application in health.

- Motivate self-learning e-learning.

- Share the teaching scenario among already trained students to capacite others, through visual thinking, the Professional students in the specific detailed concepts.

2. Professional Training Area:

- Encourage the participation of students. using active and contextualized methodologies that facilitate the participation and involvement of the student as well as the use of communication strategies based on the role to be developed in the experience.

- Encourage teaching-learning habits and professional procedures. 
- Create a climate in the classroom of collaboration and positive communication.

- Encourage self-taught learning by focusing attention on practical issues.

\section{Methodology}

The contextualized methodology to be used in this proposal contains the following steps:

A. University students:

1. Attracting university students to participate in the experience.

2. Conducting an initial training seminar for volunteers university students who wish to participate in the experience, which will consist of two parts:

a. Session in which it will be held to presentation of the proposal, objectives, methodology to be followed and knowledge to be achieved. In addition, a theoretical-practical explanation of visual thinking.

b. Session of exposition of the specific knowledge to be acquired in order to transform with visual thinking and share in the university teaching scenarioprofessional training.

3. Motivational presentation for self-learning e-learning about the tool. Study outside the classroom of the theoretical-practical contents to be transmitted (flipped classroom).

4. Realization of the teaching material using visual thinking.

B. Carry out the transversal experience in university teaching-professional training.

C. Experience evaluation: A self-administered questionnaire based on the Likert scale:

1. Evaluation of the knowledge acquired.

2. Assessment of the degree of acceptance, degree of satisfaction with the experience and the difficulties encountered.

Tool Visual thinking is a creative methodology of reflection and action that is used to process information through the use of drawings, images, connectors, graphics, words and numbers in a simple way. It is structured in four steps or phases:

1. VISUAL MAPPING Search and collect the most relevant information on the subject that you want to work.

2. VISUAL EXPLORE. Select the data that interests us and start to pose grouping patterns using six questions: What, Who, When, Where, Why and how. In this way we are able to visualize the most relevant data.

3. VISUAL BUILDING. Interpretation and transformation of words into images that is constructing them visually. Depending on the data there will be different ways of visualizing it.

4. VISUAL TESTING. Communicate clearly and concisely what you want to express, supporting a story linking data and drawings. 
The most outstanding benefits of this schematization technique are, on the one hand, paying more attention to identify what is important and relating ideas and on the other it allows us to remember in a better way, since conceptual and visual memory are used.

\section{Implementation of the proposal}

The steps that we have implemented are the followings:

\section{Step-1}

\section{days}

15

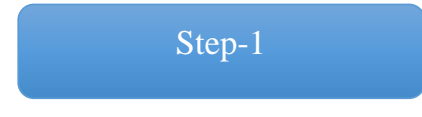

Attracting university students to participate in

the experience

3 physiotherapy

students $\downarrow$

\section{Volunteers}

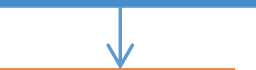

3 engineering students

Initial training seminar university students

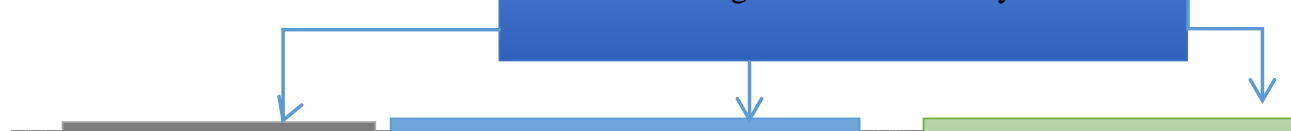

Presentation of proposal
Exposition of the specific

knowledge
Exposition a theoricalpractical Visual Thinking 


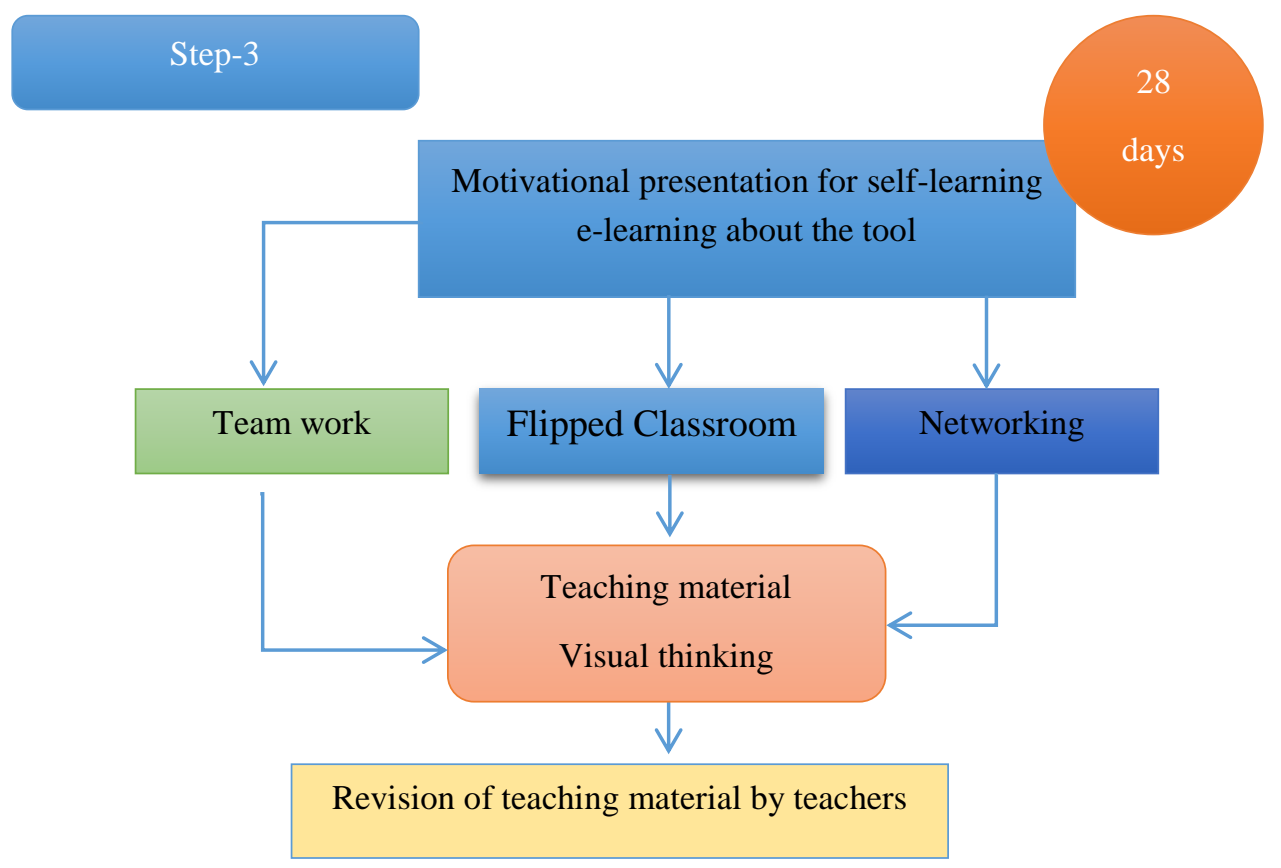

\section{Step-4}

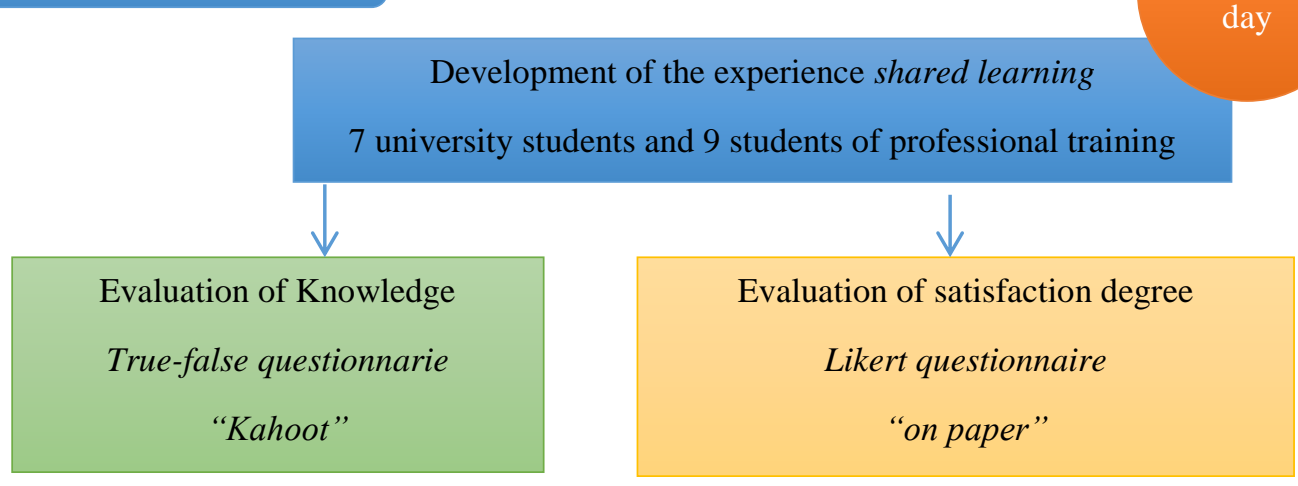

Figure 1. Implementation of the proposal 


\section{Results}

Being a proposal, we can talk about expected results, closely related to the contribution of the implementation of this teaching tool and the cross teaching experience sharing scenarios. For these reasons, we expect the following results (tables 1 and 2):

1. Acceptance of the experience by the students.

- University students.

- Professional Training students.

2. Satisfaction of the experience.

Table 1. Expected results on acceptance and satisfaction.

\begin{tabular}{ccc}
\hline & $\begin{array}{c}\text { Acceptance } \\
\text { Teaching Experience }\end{array}$ & $\begin{array}{c}\text { Satisfaction } \\
\text { Students }\end{array}$ \\
\hline University Students & $100 \%$ & $100 \%$ \\
& Good-Very Good & Moderate-High \\
Professional Training & $80 \%$ & $75 \%$ \\
Students & Good-Very Good & Moderate-High \\
\hline
\end{tabular}

3. Participation of Professional Training Students.

4. Acquisition of visual thinking knowledge.

5. Knowledge about the use of thermography in health and its theoretical bases, based on the contextualized skills and competencies of each degree.

Tabla 2. Expected results on acquired knowledges.

\begin{tabular}{ccc}
\hline & \multicolumn{2}{c}{ Acquired Knowledges } \\
\hline & Visual thinking & $\begin{array}{c}\text { Thermography in } \\
\text { Health }\end{array}$ \\
\hline University Students & $100 \%$ & $100 \%$ \\
Professional Training & Adequate-Very Adequate & Adequate-Very Adequate \\
Students & $90 \%$ & $75 \%$ \\
& Adequate-Very Adequate & Adequate-Very Adequate \\
\hline
\end{tabular}


After the implementation of the experience we have obtained the result of the evaluation:

- Acquired knowledge's: 72,86\% correct answers and 27,14\% incorrect answer.

- Acceptance and satisfaction: the expected results they match with the results obtained.

\section{Conclusions}

This type of learning-teaching activities are very interesting because they motivate students and provide them with a continuous added value that will allow them to discover and strengthen skills that will be a great help in their learning processes incorporating this new approach.

Students consider the experience of sharing learning as very satisfying. The knowledge acquired through visual thinking is considered good or very good

Sharing teaching scenarios University-Professional Training is engaging for the implementation of competencies necessary for professional development.

\section{References}

Argos, J. et al. (2013). La evaluación de los aprendizajes de los estudiantes en el marco del Espacio Europeo de Educación Superior ( EEES ): sus prácticas , preferencias y evolución. European Journal of investigation in health, psychology and education. 3(3), pp.181-194.

Gardner, H. (2010). La inteligencia reformulada: las inteligencias múltiples en el siglo XXI. Paidos Ibérica.

Roam, D. (2010). Tu mundo en una servilleta. 9edición, Gestión 2000.

Tocci, A.M. (2013). Estilos de aprendizaje de los alumnos de ingeniería según la programación neurolinguiística. Revista de estilos de aprendizaje, 12(12), pp.167-178. Available at: https://dialnet.unirioja.es/servlet/articulo?codigo $=4563646 \&$ orden $=1 \&$ info= link\%5Cnhttps://dialnet.unirioja.es/servlet/extart?codigo=4563646.

Velásquez, B. et al. (2006). Neuroscientific Theories of Learning and Their Implication in the Knowledge Construction of University Students. Tabula Rasá, 5, pp.229-245.

Uv.es. (2018). Convocatoria de proyectos de innovación educativa y mejora de la calidad docente, curso 2018/19. Available at:

https://www.uv.es/sfpie/innovacio/convo_inno_1819/convoinno1819 